\title{
Mechanical induction and competence in epithelial morphogenesis.
}

\author{
Aurélien Villedieu, Floris Bosveld and Yohanns Bellaïche
}

Institut Curie, PSL Research University, CNRS UMR 3215, INSERM U934, F-75248 Paris Cedex 05, France.

Sorbonne Universités, UPMC Univ Paris 06, CNRS, CNRS UMR 3215, INSERM U934, F-75005, France.

Corresponding authors: yohanns.bellaiche@curie.fr

\begin{abstract}
Identifying the mechanisms that govern the precise sequence of tissue deformations and flows during development is a major topic in developmental biology. Recent studies have explored how the deformation or the flow of a tissue region can be induced by the activity of a neighboring region through mechanical coupling. Such a coupling process is akin to chemical induction, whereby differentiation in a region of competent cells is stimulated by a neighboring region through chemical induction: we therefore propose to name this phenomenon "mechanical induction". Focusing on examples of mechanically induced epithelial flow or planar deformation in vivo, this review aims at discussing the processes driving mechanical induction and the competence factors modulating the induced morphogenesis, in order to highlight the importance of integrating tissue and inter-tissue scales to understand morphogenesis.
\end{abstract}

\section{Keywords}

Epithelial morphogenesis, mechanical forces, tissue and organism scales, mechanical properties, mechanotransduction

\section{Introduction}

During development, the reproducible sequence of tissue flows and deformations ensure that organisms acquire their correct shape. It is now well established that these tissue dynamics can result from the activity of the cells composing the tissue, either as a result of cell junction remodeling driven by the contractile medial and cortical acto-myosin networks [1] [2] [3], or due to the traction forces exerted on the extracellular environment by cellular protrusions [4] [5] [6] [7] [8]. However, the morphogenesis of a given tissue region can also be controlled nonautonomously through mechanical coupling, by the mechanical forces generated in neighboring tissues. A good example of such cooperation, whereby both autonomously and nonautonomously generated mechanical forces drive tissue morphogenesis, is Drosophila germband extension [9]. Within the germ-band tissue, the acto-myosin-dependent contraction of the dorsal-ventral cell junctions provides a force which promotes the convergent-extension of the tissue through cell rearrangements [8], while through mechanical coupling, the active invagination of the adjacent endoderm generates a pulling force further promoting germ-band extension [10] [11] (Figure 2B). Thus, understanding the deformation of a given region not only require to study the force-generating processes that occurs within it, but also to take into account the dynamics of the tissues that are mechanically coupled to it, thus replacing it into a larger spatial scale. 
The molecular mechanisms of force generation driving autonomous tissue deformations have been extensively reviewed elsewhere [12] [13] [14]. In this review, we bring together and discuss examples of non-autonomous tissue morphogenesis, focusing on the in vivo epithelial tissue flow and surface changes that are regulated by extrinsic mechanical forces in animal systems. To describe these morphogenetic events, we propose to extend the conceptual framework used to describe the phenomenon of induction, formalized following Spemann and Mangold's pioneering experiments [15]. In the framework of classical chemical induction, an inducer region controls the differentiation of neighboring responder tissues insofar as these tissues are competent, i.e. they can interpret and respond to the chemical signals sent by the inducer (Figure 1). In analogy, here we use the terms "mechanical responder" and "mechanical inducer" to describe the tissue regions that deform or flow non-autonomously (responder) due to the propagation of autonomously generated deformation or flow of a neighboring tissue region (inducer). The ability of the responder region to deform or flow under external mechanical stress will be referred to as mechanical competence (Figure 1).

While many different examples of mechanically induced morphogenesis have been documented in both vertebrate and invertebrate model systems, to date a coherent classification of these examples is still lacking. In this review, we first establish a typology of mechanically induced morphogenetic events based on the geometry of the contact zone between the inducer and the responder regions. A description of each example is provided in the figure legends (Figures 2-4). We will then discuss that the material properties of the responder region and its capacity for mechanotransduction are two factors of mechanical competence regulating the induced flows and deformations.

\section{Typology of mechanically induced morphogenesis: different geometries for different outcomes.}

When the inducer and the responder constitute two adjacent epithelial regions, their contact zone corresponds to an edge of the responder. In this configuration, the induced morphogenesis depends on the direction of the forces exerted on this edge. We will first examine cases where these mechanical forces are orthogonal to the edge, and subsequently where they are tangential to the edge (Figures $2 \mathrm{~A}$ and $3 \mathrm{~A}$ ).

\section{Edge orthogonal forces}

Depending on whether the responder region has free edges or not, edge orthogonal pulling forces can either give rise to tissue translation or tissue deformation (Figure 2, in blue). First, if the responder region has no edges that are attached to other structures, the tensile force imposed by the inducer region may cause the responder region to move without stretching. This accounts for example for the collective migration of Drosophila border cells [16], or for the migration of the lateral line of the zebrafish [17] (Figure 2C). On the other hand, if the rear of the responder is connected to other tissues [18], to a rigid extracellular matrix [19] or if all the edges of the responder region are connected to the inducer region, a tension field can develop across the responder region, causing it to stretch or to undergo convergent-extension (Figure 2B and DJ). At the cell scale, such induced deformations are associated with cell shape changes [10] [11], divisions and cell rearrangements [18] [20] [21] (Figures 2B, D, F and G). 
The orthogonal pulling forces applied to the edge of the responder region can result from various morphogenetic processes within the inducer region (Figure 2, in red). First, invagination or in-plane contraction of the inducer region may cause pulling forces to be exerted on the edge of the responder region. This mechanism of mechanical induction has been extensively documented in invertebrate systems in particular (Figures 2B, E, G and H). Pulling forces can also be exerted by an acto-myosin ring or a supracellular acto-myosin cable bordering the responder zone (Figures 2F, I and J). Finally, traction forces exerted by the cells of the inducer region through protrusions can generate pulling forces at the edge of the responder region. This migratory force is involved in collective migration [22] [23] (Figure 2C) and in the convergentextension of tubular structures such as the vessels of the Drosophila tracheal system [18] [24], the murine blood vessels [25] and sea urchin archenteron [26] (Figure 2D).

\section{Edge tangential forces}

In an alternative geometrical configuration, the inducer region exerts forces tangentially to its contact zone with the responder region (Figure 3A). Such forces can arise from the contraction of the inducer region in a direction parallel to the contact zone, and can induce swirling flows within the responder zone. The swirling movements illustrate the tissue fluidity of the responder region and these flows have been successfully modeled using the conceptual framework of hydrodynamics [27] [28] [29].

An inducer tissue region producing tangential forces can be found in the Drosophila embryo during gastrulation [27]. Here, the cells of the mesoderm undergo apical constriction, thereby inducing a swirling movement of the neighboring cytoplasm in the transverse plane, which subsequently results in a flow of cells towards the inducer region in the apical plane (Figure 3B). Similarly, tangential forces can result in swirling movements within the epithelial tissue plane itself, as a result of a shrinkage of the inducer-responder contact zone due to the in-plane contraction of the inducer region [28] [29] (Figure 3C-D). Reciprocally, elongation of an inducer region along the contact zone can induce elongation of the responder region. This phenomenon is exemplified by the convergent-extension of the C. elegans epidermis during early body elongation [30] [31] (Figure 3E).

\section{Surface forces}

When the inducer region is not in the same plane as the responder tissue, the contact zone giving rise to an induced deformation is no longer an edge, but an entire surface (Figure 4A). Surface forces can arise from the mechanical interaction between a superficial epithelial layer and the deep layers in contact with it [32] [33] [34]. For example, during Xenopus epiboly, the deformation of the deep mesenchymal layers favors the spreading of the superficial layer [32] (Figure 4B). Conversely, the autonomous deformation of the superficial epithelial layer can induce the deformation of the deep layers, as occurs during zebrafish epiboly [33] (Figure 4C). Depending on the geometry of the contact surface and the direction of the forces, a surface interaction can cause a simple spreading pattern to emerge, like the spreading of the Xenopus superficial layer (Figure 4B), or result in a swirling pattern, as found during zebrafish epiboly [34] (Figure 4D). Finally, surface forces can also result from the interaction of a tissue with the underlying muscles. Muscle-dependent epithelial morphogenesis has been elegantly demonstrated during the final phase of $C$. elegans body elongation, where the convergentextension of epidermal cells depends on muscle contractile activity [35] (Figures 3E and 4E). 


\section{Mechanical competence: from responder material properties to mechanotransduction.}

In the framework of mechanical induction, the behavior of the responder zone can be compared to the behavior of a soft material experiencing external forces. Under external forces, a soft material can be deformed like a solid (either reversibly and elastically, or irreversibly and plastically) and like a fluid. In all these cases, the different mechanical properties of the material (respectively its stiffness, yield strain and viscosity) control the amplitude of its deformation and flow [36]. We thus propose to consider the mechanical properties of the responder region as factors of mechanical competence (Figure 1). Besides, a living tissue is an active material that can react biochemically to external forces through mechanotransduction pathways. In this regard, mechanotransduction can also be considered as a factor of mechanical competence.

\section{Permissiveness for the induced deformation}

The emergence of mechanically induced plastic and fluid tissue deformations is favored by cell neighbor exchanges within the responder tissue [21] [29] [37] [38] [39] [40] [41]. Such exchanges can occur as a result of cell rearrangements, which can be favored by a low level of intercellular adhesion. Indeed, a decrease in cadherin-mediated intercellular adhesion has been linked to a more deformable state, favoring cell rearrangements and responder tissue extension [37] [38] (Figure 2C, Figure 4C). The contractility of the cortical acto-myosin network, associated with the cadherin adherens junction, is also an important regulator of mechanical competence by regulating intercellular adhesion. In the context of wound healing, it was demonstrated that decreasing Myosin II contractility decreased the tension at the intercellular contacts of the responder zone, which favored its deformation by stimulating cellular rearrangements and accelerated wound closure. On the other hand, increasing the contractility rigidified the intercellular contacts, reduced the deformation of the responder zone and slowed down wound closure [21] (Figure 2H). Finally, cell division has been identified to promote cell neighbor exchanges and thus as being necessary for the mechanically induced deformations in the deep layers during zebrafish epiboly [38] or during the gastrulation of quail and chicken [29] [41] (Figures 4C, Figure 3D).

\section{Resistance to the induced deformation}

High stiffness, yield strain or viscosity of the responder region are determining factors in the inhibition or the canalization of the induced deformation. For example, the anisotropy of stiffness of the $C$. elegans epidermal cells prevents their dorso-ventral stretching, allowing their stretching to be canalized along the anterior-posterior axis [31] (Figure 3E). The interaction of the responder tissue with a rigid substratum can be an additional factor that locally increases its resistance to mechanically induced deformations and flows. For example, the local adhesion to the vitelline membrane explains the absence of serosa flow in response to the neighboring contraction of the embryo during Tribolium gastrulation [43] (Figure 2E).

\section{Mechanotransduction}

In addition to inducing a mechanical response within the responder region, external mechanical forces can also trigger a chemical response by activating mechanotransduction pathways. Activation of these pathways further tune the responder tissue mechanical properties to the mechanical stimulus enabling it to deform, which can occur through the modulation of either the cellular adhesion or the cytoskeleton properties of the responder cells. For example, during Drosophila pupal wing morphogenesis, a mechanotransduction pathways is activated in the 
wing blade by the contraction of the hinge to regulate the turn-over of cadherin adhesion complexes, thereby fluidizing the wing tissue and favoring its elongation [37] (Figure 2C). On the other hand, during $C$. elegans embryogenesis, the contractile activity of the muscles triggers mechanotransduction pathways in the epidermal cells that lead to changes in their cytoskeleton architecture and their polarity, which are essential for proper elongation of the embryo [35] [42] [44] [45] (Figure 4E). Combined, these two examples illustrate that the responder tissue's ability to deform upon external forces, or its mechanical competence, relies not only on its initial mechanical properties but also on its capacity to chemically respond to these forces.

\section{Conclusion}

The study of epithelial morphogenesis is marked by mechanistic models linking the deformation of a region with the active processes taking place within it [1] [2] [3] [4] [5] [6] [7] [8] [12] [14]. While these models of autonomous deformations have greatly advanced our understanding of epithelial morphogenesis, the importance of external forces exerted by surrounding tissue regions should not be overlooked. The numerous examples presented in this review illustrate that the deformation of an epithelial region is not necessarily self-reliant, and also depend on the mechanical forces exerted on it by its surroundings. Furthermore, cellular processes that are well explained mechanistically by autonomous processes, such as cell shape changes [1] [2] or cellular rearrangements [6] [8], can also non-autonomously emerge when tissues are exposed to external mechanical forces [10] [11] [18] [20]. While the integration of cellular phenomena is crucial for understanding morphogenesis at the tissue level, understanding phenomena occurring at the tissue and inter-tissue levels (like mechanical induction) is also important for understanding cellular processes and the emergence of organism shape. Thus, identifying the regions that are the source of mechanical forces, studying the mechanical properties of the responder regions and characterizing the mechanotransduction pathways are key aspects to further advance our multi-scale understanding of morphogenesis. We believe that the conceptual framework of mechanical induction and competence provided in this review will facilitate the formalization of epithelial morphogenesis in the context of an entire developing organism.

\section{Conflict of interest statement}

Nothing declared.

\section{Acknowledgments}

We are grateful for F. Graner and E.L. Alpar for comments on the manuscript. Work in Bellaïche lab is funded by CNRS, INSERM, Curie Institute, ARC (SL220130607097), ANR Labex DEEP (11-LBX0044) and PSL (ANR-10-IDEX-0001-02) grants. AV was supported by Sorbonne Université (Paris) and FRM grants (FDT201805005805). 
Figure 1: Classical chemical induction versus mechanical induction.

This diagram illustrates the analogy between classical chemical induction (grey font) and mechanical induction (black font), whereby the signal sent by the inducer tissue (red) results in an effect in the responder tissue (blue). For classical induction the signal is a secreted morphogen, while for mechanical induction, the signal is a mechanical force. The competence of the responder (green) refers to the ability of the signal-receiving tissue to respond to the signal sent by the inducer. In classical induction, the secreted signal induces a cell fate change in the responder tissue, whereas in mechanical induction, the mechanical signal triggers a morphogenetic response (deformation or flows). For all figures, identical color coding for inducer, responder and competence is used. 
Figure 2: Mechanically induced morphogenesis resulting from edge orthogonal forces.

(A) Schematic representation of the application of orthogonal forces to the edge of a responder region. (B) The endoderm of Drosophila actively invaginates during embryogenesis [46], and it has been shown that this event causes a pulling force that promotes germ-band extension [10] [11]. Not only do the cells of the germ-band surrounding the invagination zone show a cellular stretching gradient [10], but they also undergo cell rearrangements due to the tensile forces imposed by the invagination of the endoderm [11]. Thus, in the germband, the convergent-extension is not only caused by autonomous active mechanisms [8], but is also completed by a mechanical coupling with a surrounding actively deforming tissue. (C) During Drosophila oogenesis, border cells migrate in a collective fashion [16]. Cells at the front of the population, leader cells, exert traction forces on their environment, inducing the passive displacement of the cells at the back of the population, follower cells. (D) In the Drosophila embryo, the migratory activity of a differentiated cell at the end of the trachea, the tip cell, provides the force necessary for the elongation of the stalk cells constituting the rest of the vessel. As a result of this external force, not only do the stalk cells stretch, but they also show rearrangements, contributing to the convergent-extension of the vessel. Remarkably, laser ablation of the base of the vessel shows that a basal anchorage of the vessel is necessary to put the vessel under tension and to drive its convergent-extension [18]. (E) During Drosophila dorsal closure, the contraction of the amnioserosa acts as a major force driving the flow of adjacent epidermal tissues [2] [47] [48]. (F) Wound closure is characterized by the assembly of an acto-myosin cable surrounding the wound site [49]. By contracting, this acto-myosin cable is proposed to promote cell flows and rearrangements in the tissue surrounding the wound, leading to wound closure. Indeed, local tissue fluidization upon downregulation of junctional tension favors such mechanically induced deformations [21]. (G) During Drosophila metamorphosis, the contraction of the proximal part of the wing, the hinge, is synchronized with the extension of the distal part of the wing, the blade. Microsurgery experiments severing the blade from the hinge show that coupling with the hinge is necessary for blade rotation and elongation [50]. Blade extension is marked not only by cell stretching, but also by cell rearrangements [20]. It should be noted that a distal attachment of the wing to the rigid apical extracellular matrix that surrounds it is necessary to create an anisotropic force along the wing blade and allows for its extension [20] [19]. Moreover, a mechanotransductive pathway increases E-cadherin turn-over, which favors cell rearrangements within the extending blade [37]. (H) The contraction of the embryonic tissues and the flow of the extra-embryonic tissue (the serosa) of the Tribolium embryo can be faithfully predicted from Myosin II distribution. However, a local attachment to the apical extracellular matrix (comparable to pupal wing distal attachment, see Figure 2G) locally restricts the mechanically induced serosa flows [43]. (I) During head involution of the Drosophila embryo, acto-myosin circumferential cables separating each parasegment drive both the flow of the epidermis toward the head and its stretching. Interestingly, the geometry of the embryo, showing a decreasing diameter towards the head, enables the conversion of the contractility of the circumferential cables into a sliding movement [51]. (J) During zebrafish epiboly, an acto-myosin-rich ring is present in the yolk and promotes the spreading of the enveloping surface layer [52]. The curved geometry of the embryo could be thought of as the driver of ring progression (as during Drosophila head involution, see Figure 2l), however, when the embryo is artificially flattened, the cable continues to progress. It is instead a radial friction force generated by actin retrograde flows that enable the ring to progress [52].

In red, mechanical inducer and its behavior. In blue, mechanical responder and induced behavior. In green, modulators of responder behavior. Arrows indicate the direction of the mechanical forces. 
Figure 3: Mechanically induced morphogenesis resulting from edge tangential forces.

(A) Schematic representation of the application of tangential forces to the edge of a responder region. (B) During Drosophila gastrulation, multicellular cytoplasmic swirling is observed in the transverse plane, resulting from the tangential contraction of the mesoderm cell apices [27]. This cytoplasmic swirling results in a flow of the apices of the cells toward the site of contraction. (C) In zebrafish and Xenopus cranial neural crest cells, the active contraction of the rear edge results in a swirling flow in the neural crest cell cohort, which promotes a directional and collective displacement of the cells [28]. (D) The active contraction of a crescent-shaped region in the quail embryo is at the origin of swirling movements observed during gastrulation [29]. By fluidizing the tissue by promoting cell rearrangements, cell divisions are essential to achieve these flows [29] [41]. (E) At the end of its development, the $C$. elegans embryo undergoes a dramatic body axis elongation. During this process, the lateral epidermal cells show an active convergent-extension along the anterior-posterior axis, while dorsal-ventral cells expand non-autonomously as a result of the activity of the lateral cells [30] [31]. Interestingly, the assembly of a network of parallel actin fibers allows dorsal-ventral cells to canalize their mechanically induced deformation along the anterior-posterior axis, thus contributing to the body's overall elongation [31].

In red, mechanical inducer and its behavior. In blue, mechanical responder and induced behavior. In green, modulators of responder behavior. Arrows indicate the direction of the mechanical forces. 
Figure 4: Mechanically induced morphogenesis resulting from inter-tissue surface interaction.

(A) Schematic representation of inter-tissue surface interaction. (B) During Xenopus epiboly, the deep epidermal layers undergo radial intercalations along the apical-basal axis, leading to a global decrease in the thickness of the mesenchymal tissue and an expansion of its planar surface. This induces isotropic expansion of the superficial layer [32]. (C) During zebrafish epiboly, the deep layers undergo radial cell intercalation. However, this radial intercalation is dispensable for both superficial layer expansion and yolk dome formation to occur. On the contrary, the active spreading of the superficial layer is a driving force for both deep cell layer radial intercalations and yolk doming [33]. In this context, fluidization of the deep cell layers by cell division and a local downregulation of intercellular adhesion favors the mechanically induced deformation of the deep cell layers and the yolk [38]. (D) During zebrafish gastrulation, a stripe of prechordal plate cells migrate beneath the spreading ectoderm, the direction of the two being opposite. The migrating prechordal plate cells exert friction forces on the ectoderm they migrate on, leading to a localized pulling force, which is at the center of emerging swirling flows within the plane of the ectoderm [53]. (E) The final extension of the $C$. elegans embryo depends on muscle activity, which leads to cycles of contraction/elongation of the embryo. Each cycle results in an irreversible elongation of the dorsal-ventral cells by a ratchet based mechanism relying on the shortening and the stabilization of actin fibers [42]. Thus, the rhythmic mechanical external constraints imposed by the muscles induce a gradual convergent-extension of the epidermal cells. Moreover, muscle contractions trigger a mechanotransductive response in the epidermal cells leading to the maturation of the hemidesmosomes further strengthening the intercellular adhesion [35] and the acquisition of a planar polarized cytoskeleton [44] [45], which favors convergent-extension of the epidermis.

In red, mechanical inducer and its behavior. In blue, mechanical responder and induced behavior. In green, modulators of responder behavior. Arrows indicate the direction of the mechanical forces. 


\section{References Highlights}

- Hardin, Weliky 2019 *: By combining modelling and experimental approaches, the authors propose that sea urchin archenteron elongation by cell rearrangements could be mechanically induced by migrating tip cells (similar to Figure 2D). First, modelling predicts the characteristic necking geometry of the elongated archenteron. Second, reducing archenteron cell number leads to abnormal thinning or even rupture of the elongating archenteron.

- $\quad$ Iyer 2019 *: Using the well-studied pupal wing model system (Figure 2G), the authors identified a novel mechanotransductive response of wing blade cells during its elongation. In a tension-dependent manner, p120 is excluded from the intercellular junctions and leads to an increased E-cadherin turnover. This mechanism is proposed to induce a tension-dependent fluidization of the tissue favoring its remodeling.

- Munster 2019 **: Based on the quantification of Myosin II distribution along the embryo, and under the assumption that Myosin II quantity directly reflects tissue flows, the authors predict tissue flows during Tribolium gastrulation. While most of the flow patterns are predicted by their model, the absence of ventral flows is a major deviation from the prediction. Interestingly, the inhibition of ventral flows is due to local integrin-mediated anchoring of the tissue to the vitelline membrane. Local friction thus prevents mechanically induced ventral flows from occurring (Figure $2 \mathrm{H}$ ).

- Shellard $2018 * *$ : Combining ex vivo cultures of Xenopus neural crest and in vivo imaging in zebrafish, the authors discover the presence of a contractile acto-myosin cable at the rear of cranial neural crest population. This rear contractility is shown to be necessary for collective migration. Interestingly, the bulk of neural crest cells show a swirling flowing pattern as a result of rear contraction (Figure 3C).

- Petridou 2019 **: By measuring material properties using micropipette aspiration during zebrafish epiboly (Figure 4C), the authors discover that deep cell divisions fluidize the tissue prior to enveloping layer spreading by disassembling the intercellular contacts. Interestingly, tissue fluidization is patterned, and is highest in the central region of the blastoderm deep layers. Such a spatial fluidity pattern is shown both experimentally and by modelling to favor yolk doming.

- Lardennois $2019 * *$ : By characterizing a double mutant for PAK-1 and SPC-1, the authors identify a ratchet molecular mechanism leading to the conversion of muscle contraction/relaxation cycles into an increasing epidermal convergent-extension during C. elegans body extension (Figure 4E). When epidermal cells are contracted, due to muscle activity, the actin fibers they contain are severed. PAK-1 and SPC-1-mediated stabilization of these actin fibers promote their shortening upon severing, leading to the convergent-extension of the epidermal cells and $C$. elegans body axis elongation.

- Saadaoui $2020^{* *}$ : Combining live-imaging in chicken gastrula explants and modelling, the authors show that the swirling movements accompanying primitive streak formation are mechanically induced by the contraction of a crescent-shaped inducer region and show that cell division is a competence factor necessary for the swirling movements to occur (Figure 3D).

\section{References}

1. Mason FM, Tworoger M, Martin AC: Apical domain polarization localizes actinmyosin activity to drive ratchet-like apical constriction. Nat Cell Biol 2013, 15:926-36.

2. $\quad$ Solon J, Kaya-Çopur A, Colombelli J, Brunner D: Pulsed Forces Timed by a Ratchet-like Mechanism Drive Directed Tissue Movement during Dorsal Closure. Cell 2009, 137:1331-1342.

3. Diaz-de-la-Loza M del C, Ray RP, Ganguly PS, Alt S, Davis JR, Hoppe A, Tapon N, Salbreux G, Thompson BJ: Apical and Basal Matrix Remodeling Control Epithelial Morphogenesis. Dev Cell 2018, 46:23-39.

4. Barlan K, Cetera M, Horne-Badovinac S: Fat2 and Lar Define a Basally Localized Planar Signaling System Controlling Collective Cell Migration. Dev Cell 2017, 
40:467-477.

5. Bischoff M: Lamellipodia-based migrations of larval epithelial cells are required for normal closure of the adult epidermis of Drosophila. Dev Biol 2012, 363:179_ 190.

6. Sun Z, Amourda C, Shagirov M, Hara Y, Saunders TE, Toyama Y: Basolateral protrusion and apical contraction cooperatively drive Drosophila germ-band extension. Nat Cell Biol 2017, doi:10.1038/ncb3497.

7. Shih J, Keller R: Cell motility driving mediolateral intercalation in explants of Xenopus laevis. Development 1992, 116:901-90114.

8. Bertet C, Sulak L, Lecuit T: Myosin-dependent junction remodelling controls planar cell intercalation and axis elongation. Nature 2004, 429:667-671.

9. Kong D, Wolf F, Großhans J: Forces directing germ-band extension in Drosophila embryos. Mech Dev 2017, 144:11-22.

10. Lye CM, Blanchard GB, Naylor HW, Muresan L, Huisken J, Adams RJ, Sanson B: Mechanical Coupling between Endoderm Invagination and Axis Extension in Drosophila. PLoS Biol 2015, 13:1-27.

11. Collinet C, Rauzi M, Lenne PF, Lecuit T: Local and tissue-scale forces drive oriented junction growth during tissue extension. Nat Cell Biol 2015, 17:12471258.

12. Lecuit T, Lenne P-F, Munro E: Force generation, transmission, and integration during cell and tissue morphogenesis. Annu Rev Cell Dev Biol 2011, 27:157-184.

13. Guillot $\mathrm{C}$, Lecuit $\mathrm{T}$ : Mechanics of epithelial tissue homeostasis and morphogenesis. Science 2013, 340:1185-1189.

14. Heisenberg CP, Bellaïche Y: Forces in tissue morphogenesis and patterning. Cell 2013, 153:948-962.

15. Spemann H, Hilde M: Induction of Embryonic Primordia by Implantation of Organizers from a Different Species (1923). Int J Dev Biol 2001, 45:13-38.

16. Montell DJ: Border-cell migration: the race is on. Nat Rev Mol Cell Biol 2003, 4:1324.

17. Donà E, Barry JD, Valentin G, Quirin C, Khmelinskii A, Kunze A, Durdu S, Newton LR, Fernandez-Minan A, Huber W, et al.: Directional tissue migration through a self-generated chemokine gradient. Nature 2013, 503:285-289.

18. Caussinus E, Colombelli J, Affolter M: Tip-Cell Migration Controls Stalk-Cell Intercalation during Drosophila Tracheal Tube Elongation. Curr Biol 2008, 18:1727-1734.

19. Ray RP, Matamoro-Vidal A, Ribeiro PS, Tapon N, Houle D, Salazar-Ciudad I, Thompson BJ: Patterned Anchorage to the Apical Extracellular Matrix Defines Tissue Shape in the Developing Appendages of Drosophila. Dev Cell 2015, 34:310 322.

20. Etournay R, Popovic M, Merkel M, Nandi A, Blasse C, Aigouy B, Brandl H, Myers G, Salbreux G, Jülicher F, et al.: Interplay of cell dynamics and epithelial tension during morphogenesis of the Drosophila pupal wing. Elife 2015, 4:1-51.

21. Tetley RJ, Staddon MF, Heller D, Hoppe A, Banerjee S, Mao Y: Tissue fluidity promotes epithelial wound healing. Nat Phys 2019, 15:1195-1203. 
22. Mayor R, Etienne-Manneville S: The front and rear of collective cell migration. Nat Rev Mol Cell Biol 2016, 17:97-109.

23. Theveneau E, Linker C: Leaders in collective migration: are front cells really endowed with a particular set of skills? F1000Research 2017, 6:1:11.

24. Ochoa-Espinosa A, Harmansa S, Caussinus E, Affolter M: Myosin II is not required for Drosophila tracheal branch elongation and cell intercalation. J Cell Sci 2017, 130:2961-2968.

25. Gerhardt H, Golding M, Fruttiger M, Ruhrberg C, Lundkvist A, Abramsson A, Jeltsch $\mathrm{M}$, Mitchell $\mathrm{C}$, Alitalo $\mathrm{K}$, Shima $\mathrm{D}$, et al.: VEGF guides angiogenic sprouting utilizing endothelial tip cell filopodia. J Cell Biol 2003, 161:1163-1177.

26. Hardin J, Weliky M: Cell rearrangement induced by filopodial tension accounts for the late phase of convergent extension in the sea urchin archenteron. Mol Biol Cell 2019, 30:1911-1919.

27. He B, Doubrovinski K, Polyakov O, Wieschaus E: Apical constriction drives tissuescale hydrodynamic flow to mediate cell elongation. Nature 2014, 508:392-396.

28. Shellard A, Szabó A, Trepat X, Mayor R: Supracellular contraction at the rear of neural crest cell groups drives collective chemotaxis. Science 2018, 362:339-343.

29. Saadaoui M, Corson F, Rocancourt D, Roussel J, Gros J: A tensile ring drives tissue flows to shape the gastrulating amniote embryo. Science 2020, 367:453-458.

30. Diogon M, Wissler F, Quintin S, Nagamatsu Y, Sookhareea S, Landmann F, Hutter H, Vitale N, Labouesse M: The RhoGAP RGA-2 and LET-502 / ROCK achieve a balance of actomyosin-dependent forces in $\mathbf{C}$. elegans epidermis to control morphogenesis. Development 2007, 134:2469-2479.

31. Vuong-Brender TTK, Ben Amar M, Pontabry J, Labouesse M: The interplay of stiffness and force anisotropies drives embryo elongation. Elife 2017, 6:1-49.

32. Szabó A, Cobo I, Omara S, McLachlan S, Keller R, Mayor R: The Molecular Basis of Radial Intercalation during Tissue Spreading in Early Development. Dev Cell 2016, 37:213-225.

33. Morita H, Grigolon S, Bock M, Krens SFG, Salbreux G, Morita H, Grigolon S, Bock M, Krens SFG, Salbreux G: The Physical Basis of Coordinated Tissue Spreading in Zebrafish Gastrulation. Dev Cell 2017, 40:354-366.

34. Smutny M, Ákos Z, Grigolon S, Shamipour S, Ruprecht V, Čapek D, Behrndt M, Papusheva E, Tada M, Hof B, et al.: Friction forces position the neural anlage. Nat Cell Biol 2017, 19:306-317.

35. Zhang H, Landmann F, Zahreddine H, Rodriguez D, Koch M, Labouesse M: A tension-induced mechanotransduction pathway promotes epithelial morphogenesis. Nature 2011, 471:99-103.

36. Cheddadi I, Saramito P, Dollet B, Raufaste C, Graner F: Understanding and predicting viscous, elastic, plastic flows. Eur Phys $J$ E 2011, 34:1-15.

37. Iyer KV, Piscitello-Gómez R, Paijmans J, Jülicher F, Eaton S: Epithelial Viscoelasticity Is Regulated by Mechanosensitive E-cadherin Turnover. Curr Biol 2019, 29:578-591.

38. Petridou NI, Grigolon S, Salbreux G, Hannezo E, Heisenberg CP: Fluidizationmediated tissue spreading by mitotic cell rounding and non-canonical Wnt 
signalling. Nat Cell Biol 2019, 21:169-178.

39. Petridou NI, Heisenberg C: Tissue rheology in embryonic organization. EMBO J 2019, 38:1-13.

40. Mongera A, Rowghanian P, Gustafson HJ, Shelton E, Kealhofer DA, Carn EK, Serwane F, Lucio AA, Giammona J, Campàs O: A fluid-to-solid jamming transition underlies vertebrate body axis elongation. Nature 2018, 561:401-405.

41. Firmino J, Rocancourt D, Saadaoui M, Moreau C, Firmino J, Rocancourt D, Saadaoui M, Moreau C, Gros J: Cell Division Drives Epithelial Cell Rearrangements during Gastrulation in Chick Cell Division Drives Epithelial Cell Rearrangements during Gastrulation in Chick. Dev Cell 2016, 36:249-261.

42. Lardennois A, Pásti G, Ferraro T, Llense F, Mahou P, Pontabry J, Rodriguez D, Kim S, Ono S, Beaurepaire E, et al.: An actin-based viscoplastic lock ensures progressive body-axis elongation. Nature 2019, 573:266-270.

43. Munster S, Jain A, Mietke A, Pavlopoulos A, Grill SW, Tomancak P: Integrinmediated attachment of the blastoderm to the vitelline envelope impacts gastrulation of insects. Nature 2019, 568:395-399.

44. Quintin S, Wang S, Pontabry J, Bender A, Robin F, Hyenne V, Landmann F, Gally C, Oegema K, Labouesse $\mathrm{M}$ : Non-centrosomal epidermal microtubules act in parallel to LET-502/ROCK to promote C. elegans elongation. Development 2018, 145:160 173.

45. Gillard G, Nicolle O, Brugière T, Prigent S, Pinot M, Michaux G: Force Transmission between Three Tissues Controls Bipolar Planar Polarity Establishment and Morphogenesis. Curr Biol 2019, 29:1360-1368.

46. Bailles A, Collinet C, Philippe J-M, Lenne P-F, Munro E, Lecuit T: Genetic induction and mechanochemical propagation of a morphogenetic wave. Nature 2019, 572:467-473.

47. Pasakarnis L, Frei E, Caussinus E, Affolter M, Brunner D: Amnioserosa cell constriction but not epidermal actin cable tension autonomously drives dorsal closure. Nat Cell Biol 2016, 18:1161-1172.

48. Saias L, Swoger J, D'Angelo A, Hayes P, Colombelli J, Sharpe J, Salbreux G, Solon J: Decrease in Cell Volume Generates Contractile Forces Driving Dorsal Closure. Dev Cell 2015, 33:611-621.

49. Begnaud S, Chen T, Delacour D, Mège RM, Ladoux B: Mechanics of epithelial tissues during gap closure. Curr Opin Cell Biol 2016, 42:52-62.

50. Aigouy B, Farhadifar R, Staple DB, Sagner A, Röper JC, Jülicher F, Eaton S: Cell Flow Reorients the Axis of Planar Polarity in the Wing Epithelium of Drosophila. Cell 2010, 142:773-786.

51. Czerniak ND, Dierkes K, D’Angelo A, Colombelli J, Solon J: Patterned Contractile Forces Promote Epidermal Spreading and Regulate Segment Positioning during Drosophila Head Involution. Curr Biol 2016, 26:1895-1901.

52. Behrndt M, Roensch J, Grill SW, Heisenberg C: Forces Driving Epithelial Spreading in Zebrafish Gastrulation. 2013, 257:10-14.

53. Smutny M, Ákos Z, Grigolon S, Shamipour S, Ruprecht V, Čapek D, Behrndt M, Papusheva E, Tada M, Hof B, et al.: Friction forces position the neural anlage. Nat Cell Biol 2017, 19:306-317. 

Inducer

Tissue region secreting a

\section{morphogen}

Autonomously deforming tissue region

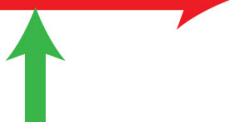

Induction of the responder

\section{Change of cell fate}

Mechanically induced tissue flow and deformation

\section{Competence of the responder}

Ability to sense and to respond to a chemical signal

Ability to deform or to respond to external forces 


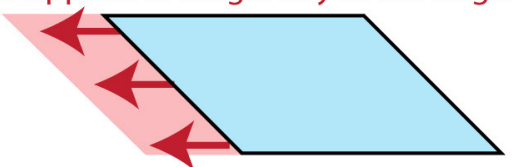

B Drosophila germ-band extension

Active invagination of the endoderm

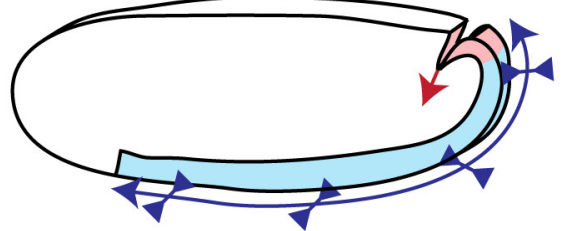

Germ-band convergent-extension

E

\section{Drosophila dorsal closure}

Contraction of the amnioserosa

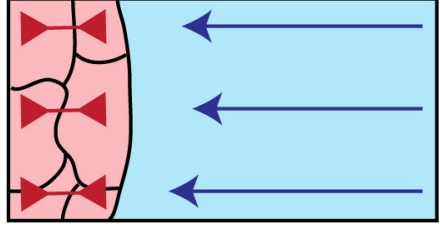

Epidermis flow

H Tribolium gastrulation

Serosa asymetric flow and spreading

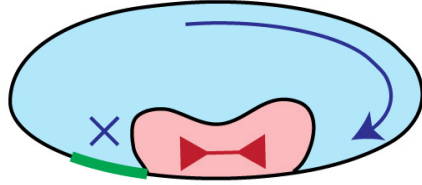

Attachment

Embryo

to the matrix
C

\section{Drosophila border cells} collective migration

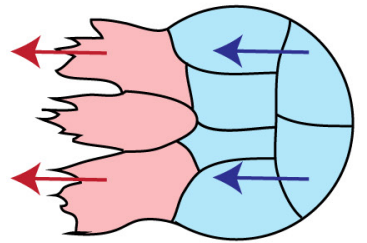

Migration of the leader cells follower cells

F

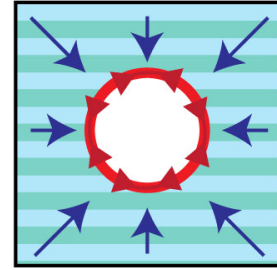

Tissue flow and cell rearrangements

Local tissue fluidity

Purse-string contraction of an acto-myosin cable

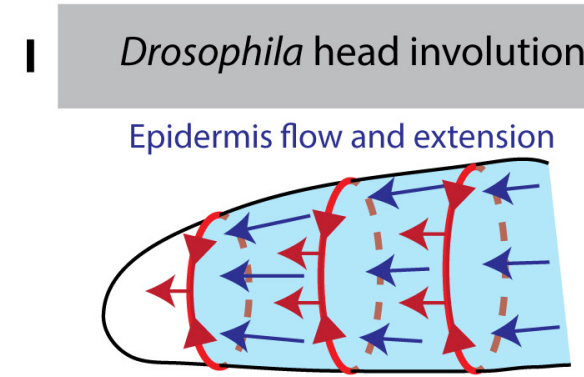

Acto-myosin cables contraction and sliding
D Drosophila trachea elongation

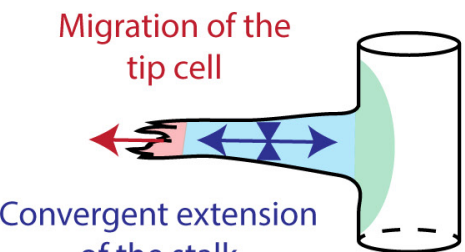

of the stalk

Basal anchorage

\section{Drosophila pupal wing extension}

Blade extension and fluidization

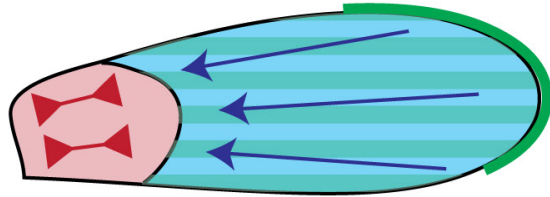

Contraction of the hinge

Distal attachement to the matrix

J

\section{Zebrafish epiboly}

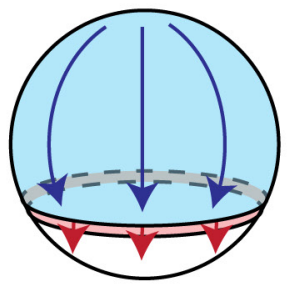

Envelopping cell layer spreading

Radial pulling of an acto-myosin ring

\section{Legend}

\begin{tabular}{|c|c|c|c|c|c|c|c|c|c|}
\hline & $\begin{array}{l}\text { Mechanical } \\
\text { inducer }\end{array}$ & & $\begin{array}{l}\text { Mechanical } \\
\text { responder }\end{array}$ & & $\begin{array}{c}\text { Modulation of } \\
\text { responder behavior }\end{array}$ & $\leftarrow$ & $\begin{array}{c}\text { Active } \\
\text { displacement }\end{array}$ & 1 & $\begin{array}{c}\text { Active } \\
\text { contraction }\end{array}$ \\
\hline$\leftarrow$ & $\begin{array}{c}\text { Induced } \\
\text { displacement }\end{array}$ & 1 & $\begin{array}{c}\text { Induced } \\
\text { contraction }\end{array}$ & $\leftrightarrow$ & $\begin{array}{l}\text { Induced } \\
\text { elongation }\end{array}$ & $x$ & $\begin{array}{l}\text { Inhibition of } \\
\text { displacement }\end{array}$ & 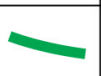 & $\begin{array}{l}\text { Anchoring to the } \\
\text { extracellular matrix }\end{array}$ \\
\hline
\end{tabular}


A Forces tangentially applied to the edge

B

\section{Drosophila gastrulation}

Cytoplasmic apico-basal swirling and resultant tissue planar flowing

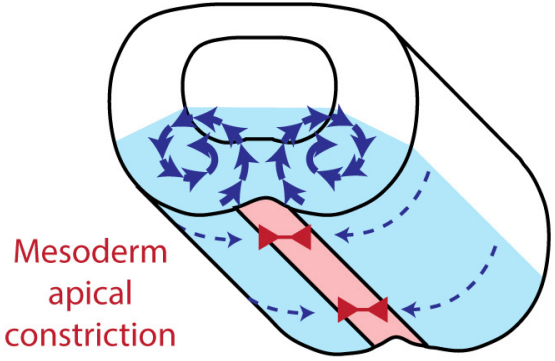

D Avian gastrulation

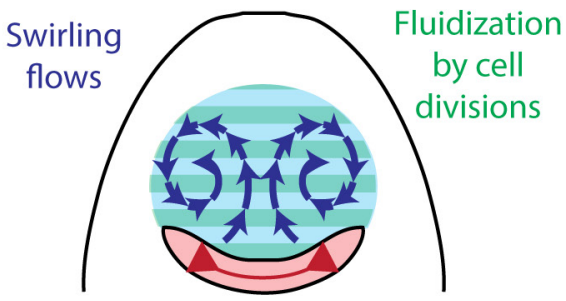

Local contraction
Xenopus or zebrafish cranial neural crest

Swirling flows

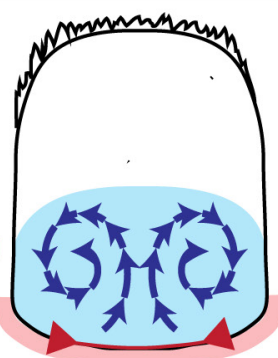

Acto-myosin cable contraction at the rear

E Early C. elegans body elongation

Lateral cells convergent extension

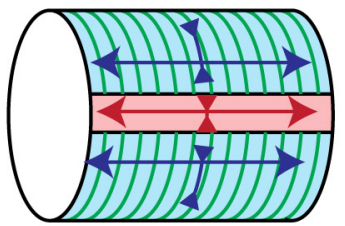

Anisotropic resistance due to an actin corset

Dorso-ventral cells convergent extension

Legend

\begin{tabular}{|c|c|l|c|l|c|}
\hline & $\begin{array}{c}\text { Mechanical } \\
\text { inducer }\end{array}$ & $\begin{array}{c}\text { Mechanical } \\
\text { responder }\end{array}$ & $\begin{array}{c}\text { Modulation of } \\
\text { responder behavior }\end{array}$ \\
\hline $\begin{array}{c}\text { Active } \\
\text { contraction }\end{array}$ & $\leftrightarrow$ & $\begin{array}{c}\text { Active } \\
\text { elongation }\end{array}$ & I) J) $)$ & Actin corset \\
\hline $\begin{array}{c}\text { Induced } \\
\text { swirling flows }\end{array}$ & -4 & $\begin{array}{c}\text { Induced } \\
\text { contraction }\end{array}$ & $\leftrightarrow$ & $\begin{array}{c}\text { Induced } \\
\text { elongation }\end{array}$ \\
\hline
\end{tabular}


A Forces applied to a surface

Xenopus epiboly

\section{Mesenchyme radial intercalation}

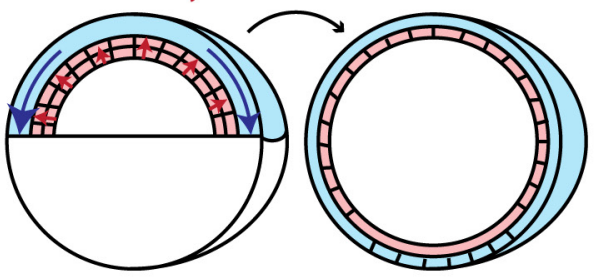

Ectoderm spreading

\section{Zebrafish epiboly}

Prechordal plate cells migration

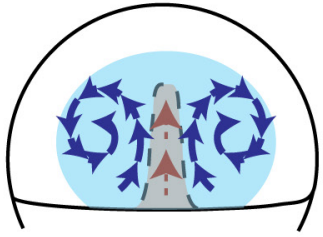

Ectoderm swirling flows

\section{Zebrafish epiboly}

Enveloping layer spreading

Fuidization by cell divisions and intercellular adhesion down-regulation

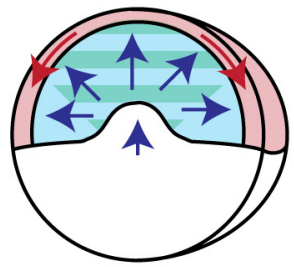

Deep cells radial intercalation and yolk doming

E Late C. elegans body elongation

\section{Muscles activity}

Ratchet shrinkage of actin fibers and mechanotransduction

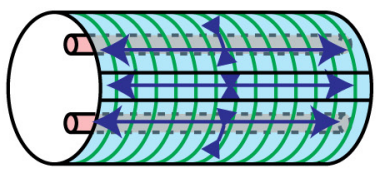

Dorso-ventral cells convergent-extension

\section{Legend}

\begin{tabular}{|c|c|c|c|c|c|}
\hline & $\begin{array}{c}\text { Mechanical } \\
\text { inducer }\end{array}$ & $\begin{array}{c}\text { Mechanical } \\
\text { responder }\end{array}$ & $\begin{array}{c}\text { Modulation of } \\
\text { responder behavior }\end{array}$ \\
\hline & $\begin{array}{c}\text { Active } \\
\text { displacament }\end{array}$ & $\left.\mu / \int\right)$ & Actin corset & $\longleftarrow$ & $\begin{array}{c}\text { Induced } \\
\text { displacement }\end{array}$ \\
\hline $\begin{array}{c}\text { Induced } \\
\text { swirling flows }\end{array}$ & - & $\begin{array}{c}\text { Induced } \\
\text { contraction }\end{array}$ & $\leftrightarrow$ & $\begin{array}{c}\text { Induced } \\
\text { elongation }\end{array}$ \\
\hline
\end{tabular}

